\title{
Spatial variability in factors influencing maternal health service use in Jimma Zone, Ethiopia: a geographically-weighted regression analysis
}

\author{
Jaameeta Kurji ${ }^{1 *}$, Charles Thickstun ${ }^{1}$, Gebeyehu Bulcha ${ }^{2}$, Monica Taljaard ${ }^{3}$, Ziqi Li ${ }^{4}$ and Manisha A. Kulkarni ${ }^{1}$
}

\begin{abstract}
Background: Persisting within-country disparities in maternal health service access are significant barriers to attaining the Sustainable Development Goals aimed at reducing inequalities and ensuring good health for all. Subnational decision-makers mandated to deliver health services play a central role in advancing equity but require appropriate evidence to craft effective responses. We use spatial analyses to identify locally-relevant barriers to access using sub-national data from rural areas in Jimma Zone, Ethiopia.

Methods: Cross-sectional data from 3727 households, in three districts, collected at baseline in a cluster randomized controlled trial were analysed using geographically-weighted regressions. These models help to quantify associations within women's proximal contexts by generating local parameter estimates. Data subsets, representing an empirically-identified scale for neighbourhood, were used. Local associations between outcomes (antenatal, delivery, and postnatal care use) and potential explanatory factors at individual-level (ex: health information source), interpersonal-level (ex: companion support availability) and health service-levels (ex: nearby health facility type) were modelled. Statistically significant local odds ratios were mapped to demonstrate how relevance and magnitude of associations between various explanatory factors and service outcomes change depending on locality.

Results: Significant spatial variability in relationships between all services and their explanatory factors $(p<0.001)$ was detected, apart from the association between delivery care and women's decision-making involvement $(p=$ 0.124). Local models helped to pinpoint factors, such as danger sign awareness, that were relevant for some localities but not others. Among factors with more widespread influence, such as that of prior service use, variation in estimate magnitudes between localities was uncovered. Prominence of factors also differed between services; companion support, for example, had wider influence for delivery than postnatal care. No significant local associations with postnatal care use were detected for some factors, including wealth and decision involvement, at the selected neighbourhood scale.

(Continued on next page)
\end{abstract}

\footnotetext{
* Correspondence: jkurj022@uottawa.ca

${ }^{1}$ School of Epidemiology and Public Health, University of Ottawa, 600 Peter

Morand Crescent, Ottawa, Ontario K1G 5Z3, Canada

Full list of author information is available at the end of the article
}

C C The Author(s). 2021 Open Access This article is licensed under a Creative Commons Attribution 4.0 International License, which permits use, sharing, adaptation, distribution and reproduction in any medium or format, as long as you give appropriate credit to the original author(s) and the source, provide a link to the Creative Commons licence, and indicate if changes were made. The images or other third party material in this article are included in the article's Creative Commons licence, unless indicated otherwise in a credit line to the material. If material is not included in the article's Creative Commons licence and your intended use is not permitted by statutory regulation or exceeds the permitted use, you will need to obtain permission directly from the copyright holder. To view a copy of this licence, visit http://creativecommons.org/licenses/by/4.0/ The Creative Commons Public Domain Dedication waiver (http://creativecommons.org/publicdomain/zero/1.0/) applies to the data made available in this article, unless otherwise stated in a credit line to the data. 
(Continued from previous page)

Conclusions: Spatial variability in service use associations means that the relative importance of explanatory factors changes with locality. These differences have important implications for the design of equity-oriented and responsive health systems. Reductions in within-country disparities are also unlikely if uniform solutions are applied to heterogeneous contexts. Multi-scale models, accommodating factor-specific neighbourhood scaling, may help to improve estimated local associations.

Keywords: Geographically weighted regressions, Spatial heterogeneity, Ethiopia, Maternal health services, Responsive health systems, Sub-national data, Equity, Local policy

\section{Background}

Policies to reduce maternal and infant mortality often target improving utilization of essential maternal health services including antenatal, delivery, and postnatal care (PNC). Linking women and their newborns to care provides opportunities to detect and manage potential complications early on [1]. Reported use of these essential services has been steadily increasing in low- and middleincome countries over the last few decades [2, 3]. However, use of delivery and postnatal services has generally been lagging behind antenatal care (ANC) $[4,5]$.

In Ethiopia, women reported 27\% ANC, 5\% delivery care and 2\% PNC use in 2000 [6]; by 2019, national levels had reached 74, 48, 34\% respectively [7]. However, substantial within-country variation was noted with several regions recording utilization levels below the national average in all three services. In order to meet Sustainable Development Goal targets 3.1 and 3.2, which tackle maternal and child mortality [8], variation in service use at sub-national levels needs to be addressed to ensure equitable progress. More importantly, understanding how local contexts change the prominence of factors affecting use is necessary to create policy strategies that are responsive to local needs and make effective use of resources.

A range of individual characteristics (such as attitude towards delivery care), inter-personal factors (like women's involvement in decision-making), and household factors (such as wealth or parity have been reported to influence maternal health service use [9-14]. However, these associations are typically quantified using regression models that assume relationships are constant across the entire study area (stationary relationships). Estimates generated from these "global models" represent averages that can mask important variation between localities [15]. Moreover, the presence of spatial dependence (where locations exhibit values that are similar to neighbouring locations) leads to spatially autocorrelated residuals that would violate the assumption of independent and identical error terms on which global models operate [16].

Exploratory work from three districts in Jimma Zone, Ethiopia, found evidence for spatial autocorrelation in the use of all three essential maternal health services [17]. Clusters with either higher (hotspots) or lower (cold spots) than expected levels of service use were identified at primary health care unit (PHCU)-, kebele(village) and sub-kebele levels. This variability in service utilization may be indicative of underlying differences between localities in both the types of factors that are important for service use as well as the magnitude of associations. In fact, the impact of community influences on maternal health service use has also been previously discussed in qualitative studies [18, 19]. Differences in neighbourhood wealth levels, norms around permission to visit health facilities, community views on giving birth at home or perceptions about quality of care developed through experiences of social network members can all contribute to regional variability in service use $[18,19]$. Contrasts in terrain and road access are also possible across different regions. If spatial mechanisms, where relationships depend on locality, have a role to play in observed patterns of service use, this needs to be appropriately explored to identify underlying factors.

The objective of this analysis, therefore, is to characterize non-stationarity in associations between explanatory factors and use of essential maternal health service use in Jimma Zone using geographically weighted regressions models.

\section{Methods \\ Study setting}

Ethiopia is situated in north-eastern Africa and has a total land area of over one million square kilometres [20]. Altitudes range between 110 below sea level around the Denakil Depression to more than $4600 \mathrm{~m}$ above sea level in the Simien Mountain ranges [20]. Jimma Zone is located in the southwest of the country within Oromia region. Administratively, Ethiopia has nine regional states which are further divided into woredas (districts) that comprise several kebeles (villages). The lowest level of the tiered health system operates at woreda level where PHCUs exist. PHCUs comprise a health centre that typically offers ANC, PNC, and basic emergency obstetric services. Each PHCU also has several communitybased health posts that serve between 3000 and 5000 
people and are staffed by health extension workers (HEWs) responsible for health promotion and preventive care in the community [21]. The Jimma University and Shenen Gibe general hospitals, which both provide comprehensive emergency obstetric care, are located in Jimma town.

This study was conducted in Gomma, Kersa and Seka Chekorsa districts. While agriculture dominates income generation in all three study districts, Gomma has substantial coffee production which is an important income source for many households [22]. Altitude ranges between 1500 and $2700 \mathrm{~m}$ across the three districts. In 2016 , there were approximately 56,700 households in Gomma, 52,300 households in Seka Chekorsa, and 43, 900 households in Kersa district [23].

The data for this study were obtained from a crosssectional, baseline household survey conducted as part of a cluster-randomized controlled trial to evaluate the effectiveness of upgraded maternity waiting homes and local leader training in improving access to maternal health services. Baseline data was collected between October 2016 and January 2017. Details about the trial are available in the published protocol [24]. Briefly, we randomly assigned 24 PHCUs (clusters) in a 1:1:1 ratio to one of the two intervention arms or to usual care. Repeat cross-sectional surveys at baseline (prior to intervention roll-out) and endline were used to collect data from random samples of 160 women per cluster during each survey round. Women were eligible if they reported a pregnancy outcome (livebirth, stillbirth, miscarriage or abortion) up to 12 months prior to each survey. The number of women interviewed were 3784 (98.5\% response rate) at baseline.

Data and GPS locations (collected using tablet computers) were available for 3727 households (98\% of enrolled households) from 96 kebeles. GPS locations were also collected for all 24 health centres. Locations were mapped using ArcGIS Pro (ESRI, Redlands, USA) and projected into Adindan UTM Zone $37 \mathrm{~N}$ prior to analysis. Administrative boundary, town location and road network data were obtained from the Jimma Zone Health Office. A map of the study area created in ArcGIS Pro is included in Fig. 1.

\section{Variables of interest}

Women's self-reported utilization of ANC, delivery care, and PNC services for their last pregnancy/birth were the main outcomes of interest. These were constructed as binary variables at the individual woman level. ANC use was defined as whether or not women reported at least four ANC contacts with service providers during their last pregnancy at a health post, health centre or hospital, where these services are normally provided. Delivery care use was defined as whether or not women reported giving birth to their last child at a health centre or hospital, where basic emergency obstetric care is usually available. PNC use was defined as whether or not women reported receiving a check from a health worker at least $1 \mathrm{~h}$ after giving birth to their last child. The $1 \mathrm{~h}$ cut-off was used to distinguish between intrapartum and postpartum care which has been reported to be conflated by women [25]. Levels of service use among women in the baseline survey were $47 \%$ for at least four ANC contacts and, $49 \%$ for delivery care and 39\% for PNC [26].

Candidate explanatory variables hypothesized to affect service use were identified based on the literature [9-14] and field experience. These were broadly categorized into individual woman characteristics, interpersonal or household elements and, health system-related considerations (Additional File 1: conceptual model). Factors hypothesized to be associated with all three services were: woman's education, health information source, danger sign awareness, prior service use, household wealth, woman's involvement in decision making, parity, home visits by HEWs and type of nearby health facility. Additionally, for ANC and delivery care use, perceived need for delivery care services, birth preparedness were considered important; availability of companion support was expected to be more relevant for delivery and postnatal care. Mode of delivery was expected to be an important factor associated with PNC use.

Frequencies and percentages (for categorical variables) and summary statistics (such as mean and standard deviation) for the continuous variable (parity) were generated to describe the study population.

Health system factors such as quality of care are important, but since they are common across entire PHCUs they are unlikely to exhibit sufficient variability at the local level required for geographically weighted regression (GWR) models. Distance between households and health centres was also not included in the models as it could confound GWR results which employ distance-based analyses [27]. Finally, husband characteristics, such as education level, and risk perceptions around complications among both women and their husbands were not included in the models since missing data reduced available sample size and could introduce selection bias. Definitions for explanatory variables hypothesized to be important factors influencing service use are provided in Additional File 2.

\section{Global regression models and presence of spatial dependencies}

Before exploring spatial variation in relationships, the presence of spatial dependency needs to be established. This is usually done by testing the residuals from global models for the presence of spatial autocorrelation. Random effects multivariable logistic regression was conducted for each outcome (i.e., ANC, delivery care, PNC) with relevant 


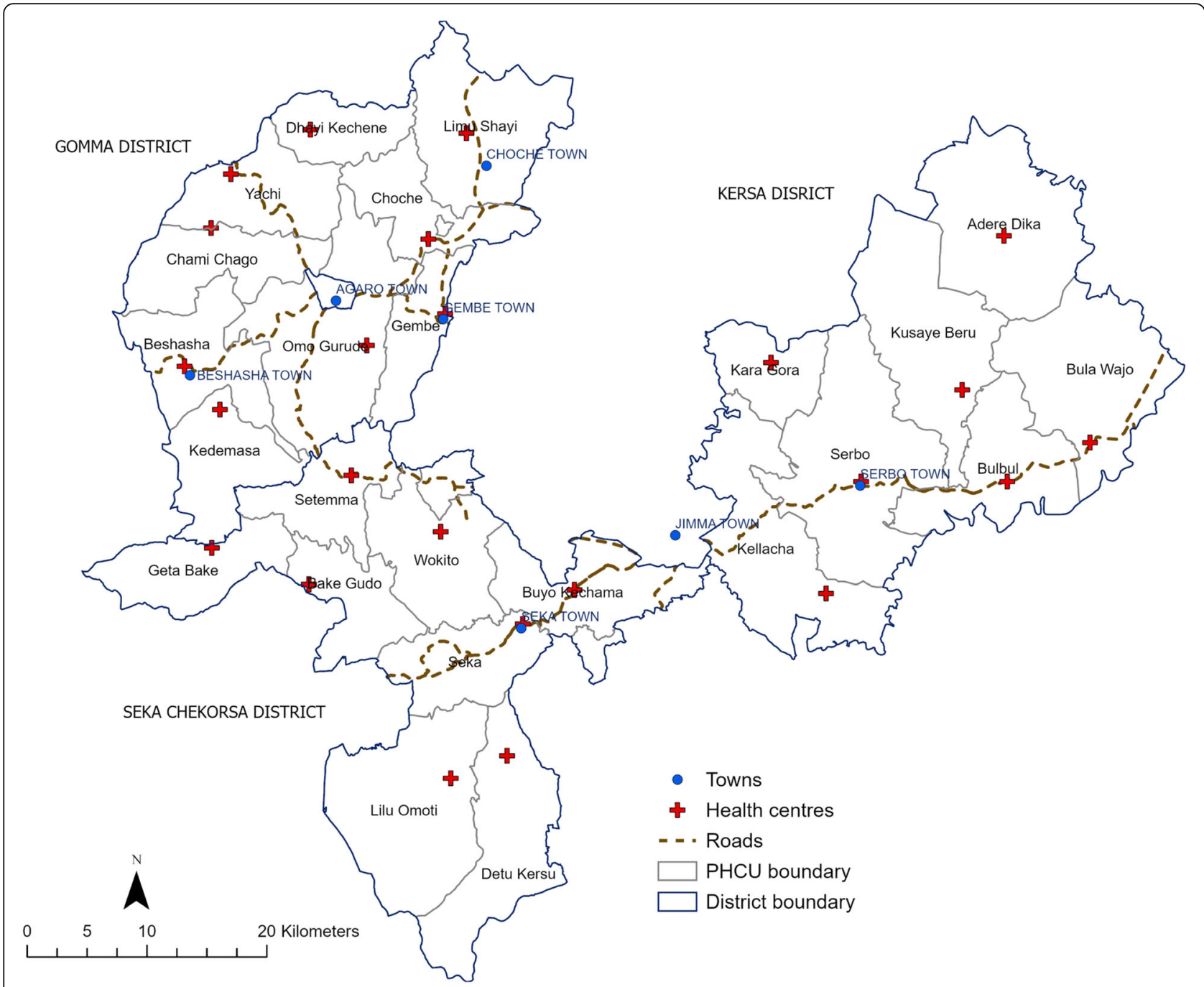

Fig. 1 Map of the study area showing locations of health centres in PHCUs, main towns, roads, PHCU and district boundaries created in ArcGIS Pro

candidate explanatory factors specified as fixed effects and PHCUs specified as random effects to account for intracluster correlation. Analysis was conducted in Stata version 15 (StataCorp, College Station, USA) and odds ratios with corresponding 95\% confidence intervals were reported for each explanatory variable. These global estimates represent the mean values across the entire study area.

Deviance residuals were then generated and tested for the presence of spatial autocorrelation using Global Moran's I spatial statistic in ArcGIS Pro. The Moran's I index generally ranges from -1 to 1 ; positive indices imply a clustering of similar values while negative indices are suggestive of more dispersed patterns [28]. A statistically significant Moran's I index would imply that a spatial correlation structure exists in the residuals that needs to be explored using models that can integrate this spatial dependence.

\section{Exploring locally varying relationships using} geographically weighted regression models

Geographically weighted regressions are an extension of conventional regression models that permit the estimation of coefficients for each location of interest (local estimates). In this way they can quantify non-stationary relationships which vary across space. The process is rooted in the first law of geography which asserts that neighbouring objects are more closely related than more distant objects [29]. As shown below, parameter estimates for $k$ independent variables are estimated for each location $i$, in this case households, specified by coordinates $\left(u_{\dot{v}} v_{i}\right)$ [15]:

$$
\log \left(\frac{\mathrm{E}\left(\mathrm{y}_{\mathrm{i}}\right)}{1-\mathrm{E}\left(\mathrm{y}_{\mathrm{i}}\right)}\right)=\beta_{0}\left(\mathrm{u}_{\mathrm{i}}, \mathrm{v}_{\mathrm{i}}\right)+\sum_{k} \beta_{\mathrm{k}}\left(\mathrm{u}_{\mathrm{i}}, \mathrm{v}_{\mathrm{i}}\right) \mathrm{x}_{\mathrm{ik}}+\mathrm{e}_{i}
$$

The "local" parameter estimates are generated using subsets of data points that are considered to be 
neighbours of household $i$. Neighbourhood is defined using spatial kernels and bandwidths parameters. The kernel is a proximity weighting function while the bandwidth is a measure of the distance decay in the kernel [15]. Whereas global models would assign the same weight to all household data points, kernels used in GWRs assign more weight to nearby households.

GWR analysis was conducted in MGWR 2.2 [30]. An adaptive, bi-square function, shown below, was used as the kernel, where weights assigned to neighbouring households ( $j$ ) decrease according to a near-Gaussian curve up to the bandwidth (b), after which they are assigned a weight of zero [15].

$$
\mathrm{w}_{\mathrm{ij}}=\left[1-\left(\mathrm{d}_{\mathrm{ij}} / \mathrm{b}\right)^{2}\right]^{2} \text { if } j \text { is an nth nearest neighbour }
$$

$\mathrm{d}_{\mathrm{ij}}$ is the distance between $i$ and $j$

In this way, the weights determine the level of contribution each household makes to the local model calibration process [15]. An adaptive rather than fixed kernel was selected to ensure that all local model calibration subsets had an adequate number of households. Fixed kernels can result in local estimates with large standard errors in areas with fewer data points when data points are not evenly distributed across the study area [15].

Optimization procedures are recommended when selecting bandwidths [15] as GWR estimates are sensitive to bandwidth choice. Large bandwidths may be unable to capture local variation and can return coefficients close to global model estimates. On the other hand, small bandwidths can result in high variability as coefficients are overly dependent on nearby points [15]. The Golden Section Search optimization technique was used to identify the optimal bandwidth that minimized the corrected Akaike Information Criterion (AICc) [15]. Optimal bandwidths were determined to be 927 households (872-2304) for ANC, 1459 households (1247-1573) for delivery care and 1560 households (1443-2296) for PNC.

\section{Model diagnostics and selection of the final local model}

The potential for multicollinearity between local coefficients has been previously described as a concern for GWRs [31]. However, subsequent simulation studies with large sample sizes $(\geq 1000)$ have demonstrated that GWRs estimates are not affected even in the presence of moderate global collinearity [32]. The results of diagnostic tests to check for multicollinearity in local parameter estimates, including condition numbers, local variance inflation factors (VIFs) and variance decomposition proportions (VDPs) were inspected nonetheless. Condition numbers greater than 30, VIFs greater than 10 and VDPs greater than 0.5 generally indicate a strong presence of multicollinearity
[33-35]. Education and nearby health facility were, thus, removed from ANC and PNC models respectively. The final combination of explanatory factors retained in the local models had no evidence of local multicollinearity.

A test for spatial variability was also run to identify which relationships were significantly non-stationary. The null hypothesis of this test is that the associations of the explanatory factor with the outcome is globally fixed; a Monte Carlo approach is used to generate an experimental distribution of the variance of local parameters for each explanatory factor to which the actual variance is then compared [15].

Statistically significant estimates identified using adjusted $p$-values from the pseudo t-tests were exponentiated and mapped as odds ratios to visualize nonstationary relationships. Under pseudo t-tests, $t$-values are computed as a ratio between the estimate and its standard deviation and compared to a critical t-value that is adjusted for multiple testing using a Bonferroni-style correction adapted for GWRs [15, 36]. The adjusted margin of error $(\alpha)$ was 0.005 for ANC, 0.009 for delivery care and 0.010 for PNC. Significant estimates were mapped in colour using natural breaks with darker shades indicating higher magnitude, while non-significant estimates were mapped in grey. Only qualitative comparisons can be made between maps for the three services as association estimates are classified differently for the same explanatory factors.

The relative performance between the global and local models was compared by inspecting the respective AICc for each model [34]. The lower AICc obtained for local models compared to global models indicated that the former has the "best fit to the data" [15] and, were therefore, more desirable options. Finally, the residuals from the GWR models were tested using Global Moran's I to see if there were any remaining spatial autocorrelation structures.

\section{Results}

\section{Characteristics of the study population}

Most women in the study area were housewives and about $45 \%$ had completed some level of education (Table 1). About half the women identified nurses as sources for birth-related information. While the majority of women were aware of at least one danger sign associated with pregnancy as well as birth, almost $60 \%$ were unaware of postpartum danger signs. In terms of prior maternal health service use, close to $60 \%$ of women had used ANC services for past pregnancies, but only half as many reported prior delivery care use. Almost all women felt delivery care was necessary for all women (94\%) and most had companion support available (78\%), were involved in decisions about delivery site (78\%) and prepared for birth (68\%). 
Table 1 Frequencies, percentages, district- and PHCU-level ranges of explanatory factors

\begin{tabular}{|c|c|c|c|c|}
\hline \multirow{2}{*}{$\begin{array}{l}\text { Characteristic } \\
\text { Individual factors }\end{array}$} & \multicolumn{2}{|c|}{$\begin{array}{l}\text { Frequency } \\
(n=3727) \\
(\%)\end{array}$} & \multirow[t]{2}{*}{$\begin{array}{l}\text { District-level range } \\
(n=3) \\
(\%)\end{array}$} & \multirow[t]{2}{*}{$\begin{array}{l}\text { PHCU-level range } \\
(n=24) \\
(\%)\end{array}$} \\
\hline & & & & \\
\hline \multicolumn{5}{|l|}{ Education level } \\
\hline None & 2068 & $(55.5)$ & $47-68$ & $31-73$ \\
\hline Primary/secondary/higher & 1659 & $(44.5)$ & $32-53$ & $27-69$ \\
\hline \multicolumn{5}{|l|}{ Occupation } \\
\hline Housewife & 2884 & $(77.4)$ & $76-80$ & $67-90$ \\
\hline Formal occupation & 843 & $(22.6)$ & $21-24$ & $10-33$ \\
\hline \multicolumn{5}{|l|}{ Danger sign awareness } \\
\hline Aware of pregnancy danger signs & 2784 & $(74.7)$ & $74-75$ & $60-93$ \\
\hline Aware of delivery danger signs & 2959 & $(79.4)$ & $78-81$ & $67-92$ \\
\hline Aware of postpartum signs & 1548 & $(41.5)$ & $40-43$ & $29-61$ \\
\hline \multicolumn{5}{|l|}{ Nurse as information source } \\
\hline Health-related information ${ }^{a}$ & 1543 & $(41.4)$ & $37-47$ & $15-53$ \\
\hline Birth-related information & 1874 & $(50.3)$ & $45-56$ & $18-66$ \\
\hline \multicolumn{5}{|l|}{ Service use } \\
\hline History of ANC use ${ }^{a}$ & 2070 & $(56.1)$ & $50-65$ & $21-83$ \\
\hline ANC use for last child & 1756 & $(47.1)$ & $38-55$ & $26-62$ \\
\hline History of delivery care use ${ }^{a}$ & 1165 & $(31.6)$ & $21-43$ & $11-51$ \\
\hline Delivery care use for last child & 1835 & $(49.0)$ & $35-64$ & 19-72 \\
\hline \multicolumn{5}{|l|}{ Attitude towards delivery care } \\
\hline Unnecessary for experienced women & 239 & $(6.5)$ & $6-7$ & $1-16$ \\
\hline Assisted delivery mode ${ }^{a}$ & 187 & $(5.0)$ & $4-6$ & $1-11$ \\
\hline \multicolumn{5}{|l|}{ Household or inter-personal factors } \\
\hline Wealthiest household group & 1184 & $(31.8)$ & $15-53$ & $6-68$ \\
\hline Companion support available & 2907 & $(78.0)$ & $70-86$ & $5-53$ \\
\hline \multicolumn{5}{|l|}{ Involved in decision making } \\
\hline About delivery site & 2916 & $(78.2)$ & $76-81$ & $54-84$ \\
\hline Health-related issues & 2656 & $(71.3)$ & $67-75$ & $59-91$ \\
\hline Pregnancy planned & 2438 & $(66.1)$ & $56-73$ & $42-81$ \\
\hline Engaged in birth preparedness and planning & 2520 & $(67.6)$ & $61-72$ & $16-52$ \\
\hline \multicolumn{5}{|l|}{ Health system factors } \\
\hline Home visit by HEW & 1251 & (33.6) & $23-39$ & $7-49$ \\
\hline \multicolumn{5}{|l|}{ Nearby health facility type/level } \\
\hline Hospital/health centre & 1751 & $(47.5)$ & $42-54$ & $28-74$ \\
\hline
\end{tabular}

${ }^{a}$ Denominators differ: Nurse as source of health information, data available for $n=3721$ (99.8\%) women only. History of ANC use, data available for $n=3688$ (98.7\%) women only. History of delivery care use, data available for $n=3682$ as $n=45$ women were first time mothers for whom history of delivery care was not applicable. Assisted delivery mode, data available for $n=3714$ women. $n=11$ had abortion outcomes and, therefore, delivery mode was not applicable while $n=2$ had missing data

When variation of these factors was examined across districts, some differences were noted in education levels, prior service use, home visits by HEWs and the type of the closest health facility. Variation across districts in household wealth was notable, with $53 \%$ of Gomma residents falling within the least poor groups but only $15 \%$ belonging to these groups in Kersa district.
Variability was also present between PHCUs, both within and across districts, and was the case for almost all potential explanatory factors. Using wealth as an example, the percentage of least poor households ranged from only $6 \%$ in Kusaye Beru PHCU (Kersa district) to $30 \%$ in Beshasha and 68\% in Dhayi Kechene PHCUs (Gomma district) (data not shown). 


\section{Global associations in service use identified by statistical regression models}

Prior use of a maternal health service was the only factor that was strongly associated with current use of all three services (Table 2). Information source, household wealth and home visits by HEWs were found to be significantly associated with both ANC and delivery care but not PNC. Additionally, attitude towards delivery care, preparing for birth and type of nearby health facility, that were not hypothesized to be important for PNC use and, thus not included in the PNC models, were significantly associated with the other two services. Being involved in decision making, lower parity and the pregnancy being planned were important for ANC use while having an assisted delivery was significantly associated with PNC use. As hypothesized, having companion support was favourably associated with both delivery and postnatal care use. Awareness of danger signs was not a significant factor associated with delivery care use.

Evidence of spatial autocorrelation in global model residuals was detected for all three services $(p<0.001)$ (results not shown).

\section{Local variation in associations of service use revealed by GWR models}

The panel of maps for ANC (Fig. 2a-i), delivery care (Fig. 3a-k) and PNC (Fig. 4a-d) depict estimates of local associations detected for each service and their respective explanatory variables. Variation in magnitude of local parameter estimates was visually apparent for all three service outcomes across most explanatory variables. However, whether or not local associations were statistically significant, the strength of the association, and at what scale the relationships appeared to vary, depended on the explanatory factor, service outcome and locality under consideration.

Comparison of results from the local GWR models and conventional global regression models revealed several things. Firstly, associations for some explanatory factors found to be statistically significant at the global level (Table 2) had widespread significant local associations as well, but differed in magnitude as illustrated by darker shades on maps. For instance, local estimates for ANC use and information source (Fig. 2a) or prior ANC use (Fig. 2c) were significant for households across most PHCUs in both Kersa and Seka Chekorsa districts as well as households in some Gomma districts kebeles. However, stronger associations between ANC use and information source could be seen in households in the northern PHCUs in Kersa district than those in the southern PHCUs (Fig. 2a). Similarly, local associations of prior ANC use among households in PHCUs along the north-western parts of Kersa district were of higher magnitude than households in Seka Chekorsa district PHCUs (Fig. 2c).
Statistically significant global associations, assumed to be relevant for the entire study area, were also found to have quite localized associations for certain factors when local model results were considered. Higher household wealth, for example, was most relevant for households in Kersa districts PHCUs and some households in kebeles in Geta Bake PHCU (Seka Chekorsa district) when it came to delivery care use (Fig. 3h). In the other areas, such as households in Gomma district, other factors such as prior service use (Fig. 3d or e) and attitudes towards care (Fig. 3f) appeared to be more relevant. Contrastingly in Kersa, a relatively poorer district than Gomma, in addition to higher wealth levels, having companion support was associated with delivery care use in the northern parts (Fig. 3g) but engaging in birth preparedness planning had significant associations with delivery care use in households in the southern kebeles (Fig. 3j).

The localities for which explanatory factors exerted an influence also differed depending on the service considered. Having nurses as an information source exhibited significant associations for both ANC and delivery care use but the areas where these associations were detected differed; for ANC use strong associations could be seen among households from PHCUs in the south-central portion of the study area coinciding with Setemma, Wokito and Bake Gudo PHCUs (Fig. 2a) while for delivery care no significant local estimates were detected for this factor in these areas (Fig. 3b). Similarly, while having companion support appeared to be important for delivery care use among households in most PHCUs in Kersa and Seka Chekorsa districts (Fig. 3g), it seemed to be relevant for fewer households concentrated mainly in kebeles from Geta Bake, Setemma and Kedemasa PHCUs for PNC use (Fig. 4d).

Interestingly, women's involvement in decision making was found neither to be neither globally (Table 2) nor locally significant with respect to delivery care use and the test for spatial variability also did not find evidence of significant non-stationarity (results not shown). Finally, both global and local estimates for several explanatory factors for PNC use such as education, wealth, and parity were not statistically significant. However, spatial variability tests suggested that there was significant non-stationarity in relationships implying that the scale at which local associations were explored may be unsuitable (results not shown).

The Global Moran's I test conducted on GWR residuals was significant for all three services, indicating that there was still some spatial autocorrelation present.

\section{Discussion}

Conventional regression models identified a series of individual, interpersonal and health system factors as 
Table 2 Results from global random effects logistic regression analysis of antenatal, delivery and postnatal care use

\begin{tabular}{|c|c|c|c|c|c|c|}
\hline \multirow[t]{2}{*}{ Potential explanatory factor } & \multicolumn{2}{|c|}{$\begin{array}{l}\text { Antenatal care } \\
(n=3687)^{\mathrm{a}}\end{array}$} & \multicolumn{2}{|c|}{$\begin{array}{l}\text { Delivery care } \\
(n=3682)^{\mathrm{a}}\end{array}$} & \multicolumn{2}{|c|}{$\begin{array}{l}\text { Postnatal care } \\
(n=3708)^{\mathrm{a}}\end{array}$} \\
\hline & \multicolumn{2}{|c|}{ OR $(95 \% \mathrm{Cl})$} & \multicolumn{2}{|c|}{ OR $(95 \% \mathrm{CI})$} & \multicolumn{2}{|c|}{ OR (95\% Cl) } \\
\hline \multicolumn{7}{|l|}{ Individual factors } \\
\hline \multicolumn{7}{|l|}{ Education level } \\
\hline None & \multicolumn{2}{|l|}{-} & \multicolumn{2}{|c|}{ Reference } & \multicolumn{2}{|c|}{ Reference } \\
\hline Primary/secondary/higher & - & & 0.77 & $(0.63,0.93)$ & 1.09 & $(0.90,1.33)$ \\
\hline \multicolumn{7}{|l|}{ Pregnancy danger signs } \\
\hline Not aware & \multicolumn{2}{|c|}{ Reference } & \multicolumn{2}{|l|}{-} & \multicolumn{2}{|l|}{-} \\
\hline Aware & 1.21 & $(1.02,1.44)$ & - & & - & \\
\hline \multicolumn{7}{|l|}{ Delivery danger signs } \\
\hline Not aware & \multicolumn{2}{|l|}{-} & \multicolumn{2}{|c|}{ Reference } & \multicolumn{2}{|l|}{-} \\
\hline Aware & \multicolumn{2}{|l|}{-} & 1.22 & $(0.98,1.51)$ & \multicolumn{2}{|l|}{-} \\
\hline \multicolumn{7}{|l|}{ Postpartum danger signs } \\
\hline Not aware & \multicolumn{2}{|l|}{-} & - & & Refere & \\
\hline Aware & - & & - & & 1.22 & $(1.02,1.46)$ \\
\hline Nurse as information source & & & & & & \\
\hline Health information & & & & & & \\
\hline No & Refer & & - & & Refere & \\
\hline Yes & 2.08 & $(1.79,2.41)$ & - & & 0.94 & $(0.79,1.13)$ \\
\hline Delivery information & & & & & & \\
\hline No & - & & Refer & & - & \\
\hline Yes & - & & 2.17 & $(1.82,2.58)$ & - & \\
\hline Antenatal care use & & & & & & \\
\hline No prior use & Refer & & & & - & \\
\hline Prior use & 1.87 & $(1.61,2.18)$ & - & & - & \\
\hline No use last pregnancy & - & & Refer & & & \\
\hline$>=4$ last pregnancy & - & & 2.06 & $(1.73,2.44)$ & & \\
\hline Delivery care use & & & & & & \\
\hline No prior use & - & & Refer & & - & \\
\hline Prior use & - & & 9.56 & $(7.67,11.92)$ & - & \\
\hline No use last pregnancy & - & & - & & Refere & \\
\hline Used for last pregnancy & - & & - & & 15.35 & $(12.61,18.69)$ \\
\hline Attitude towards delivery care & & & & & & \\
\hline Necessary for all & Refer & & Refer & & - & \\
\hline Not necessary for all & 0.51 & $(0.36,0.71)$ & 0.32 & $(0.22,0.47)$ & - & \\
\hline Delivery mode & & & & & & \\
\hline Not assisted & - & & - & & Refere & \\
\hline Assisted & - & & - & & 2.95 & $(1.95,4.45)$ \\
\hline Household or inter-personal $f$ & & & & & & \\
\hline Wealthiest household group & & & & & & \\
\hline No & Refer & & Refer & & Refere & \\
\hline Yes & 1.52 & $(1.30,1.79)$ & 1.36 & $(1.12,1.66)$ & 1.20 & $(0.99,1.46)$ \\
\hline Companion support & & & & & & \\
\hline Not available & - & & Refer & & Refere & \\
\hline
\end{tabular}


Table 2 Results from global random effects logistic regression analysis of antenatal, delivery and postnatal care use (Continued)

\begin{tabular}{|c|c|c|c|c|c|c|}
\hline \multirow{3}{*}{$\begin{array}{l}\text { Potential explanatory factor } \\
\text { Available }\end{array}$} & \multirow{2}{*}{\multicolumn{2}{|c|}{$\begin{array}{l}\begin{array}{l}\text { Antenatal care } \\
(n=3687)^{\mathrm{a}}\end{array} \\
\mathrm{OR}(95 \% \mathrm{Cl})\end{array}$}} & \multirow{2}{*}{\multicolumn{2}{|c|}{$\begin{array}{l}\begin{array}{l}\text { Delivery care } \\
(n=3682)^{\mathrm{a}}\end{array} \\
\text { OR }(95 \% \mathrm{Cl})\end{array}$}} & \multirow{2}{*}{\multicolumn{2}{|c|}{$\begin{array}{l}\begin{array}{l}\text { Postnatal care } \\
(n=3708)^{\mathrm{a}}\end{array} \\
\text { OR }(95 \% \mathrm{Cl})\end{array}$}} \\
\hline & & & & & & \\
\hline & \multicolumn{2}{|l|}{-} & 2.75 & $(2.20,3.43)$ & 1.64 & $(1.28,2.08)$ \\
\hline \multicolumn{7}{|l|}{ Health-related decisions } \\
\hline Not involved & \multicolumn{2}{|c|}{ Reference } & \multicolumn{2}{|l|}{-} & \multicolumn{2}{|c|}{ Reference } \\
\hline Involved & 1.33 & $(1.13,1.57)$ & - & & 1.10 & $(0.91,1.34)$ \\
\hline \multicolumn{7}{|l|}{ Delivery site decisions } \\
\hline Not involved & - & & Refer & & - & \\
\hline Involved & - & & 0.83 & $(0.67,1.02)$ & - & \\
\hline Parity & 0.92 & $(0.89,0.95)$ & 1.04 & $(0.99,1.08)$ & 0.98 & $(0.94,1.02)$ \\
\hline \multicolumn{7}{|l|}{ Pregnancy planned } \\
\hline No & \multicolumn{2}{|c|}{ Reference } & \multicolumn{2}{|l|}{ - } & \multicolumn{2}{|l|}{-} \\
\hline Yes & 1.42 & $(1.21,1.66)$ & - & & - & \\
\hline \multicolumn{7}{|l|}{ Birth preparedness } \\
\hline Did not plan & \multicolumn{2}{|c|}{ Reference } & & & \multicolumn{2}{|l|}{-} \\
\hline Planned for delivery & 1.46 & $(1.24,1.71)$ & 1.45 & $(1.20,1.74)$ & - & \\
\hline \multicolumn{7}{|l|}{ Health system factors } \\
\hline \multicolumn{7}{|l|}{ Home visit by HEW } \\
\hline No & \multicolumn{2}{|c|}{ Reference } & \multicolumn{2}{|c|}{ Reference } & & \\
\hline Yes & 1.32 & $(1.13,1.55)$ & 1.35 & $(1.13,1.62)$ & 1.14 & $(0.95,1.36)$ \\
\hline \multicolumn{7}{|l|}{ Nearby health facility type/level } \\
\hline Not hospital/health centre & \multicolumn{2}{|c|}{ Reference } & \multicolumn{2}{|c|}{ Reference } & \multicolumn{2}{|l|}{-} \\
\hline Hospital/health centre & 1.66 & $(1.44,1.92)$ & 1.98 & $(1.67,2.36)$ & - & \\
\hline
\end{tabular}

${ }^{a}$ Denominators indicate number of women for whom data was available for all candidate explanatory variables. Differences between models are reflective of differences in data available (Nurse as health information source $n=3721$; history of ANC use $n=3688$; history of delivery care use $n=3682$ and delivery mode $n=3714$ )

important for maternal health service use. Several factors such as danger sign awareness [37, 38], prior service use [39], wealth levels [40-42], parity [42-44] and whether or not a pregnancy was planned [37, 40,45], have been reported by other studies investigating service use in Ethiopia. The use of GWR models, however, uncovered the existence of spatially varying associations between service use and explanatory factors suggesting that these factors may not be uniform in their influence on service use across the study area. Thus, GWRs can potentially facilitate the exploration of place effects in ways traditional regression models cannot. Statistical regression models often "control" for place by including population composition variables (such as the proportion of educated women in a village) as proxies for local context. However, as Tunstall and colleagues explain, this is unlikely to adequately capture the complex mechanisms that gave rise to these compositional differences to begin with [46].

Understanding how geographical and social contexts shape what factors have prominence in affecting service use is essential for effective policy formulation and implementation. It is also a key component in the design of responsive health systems, which are described as being able to "anticipate and adapt to changing needs" [47]. Indeed strategies to create responsive health systems include gathering empirical evidence about the needs of the community to adapt services accordingly [48]. In localities where wealth drives service use, ensuring out-of-pocket expenses are minimized could be effective in encouraging use; whereas deploying more community health workers to promote better danger sign awareness may be more relevant in places where use is highly dependent on awareness of risks. Providing contextually-tailored care has also been identified as a fundamental dimension of equity-oriented primary health care services [49]. Once again, this underscores the need to have a clear understanding of local influences that shape use to prevent one-size-fits-all policies from perpetuating structural inequities that marginalize populations by ignoring place-specific effects. 


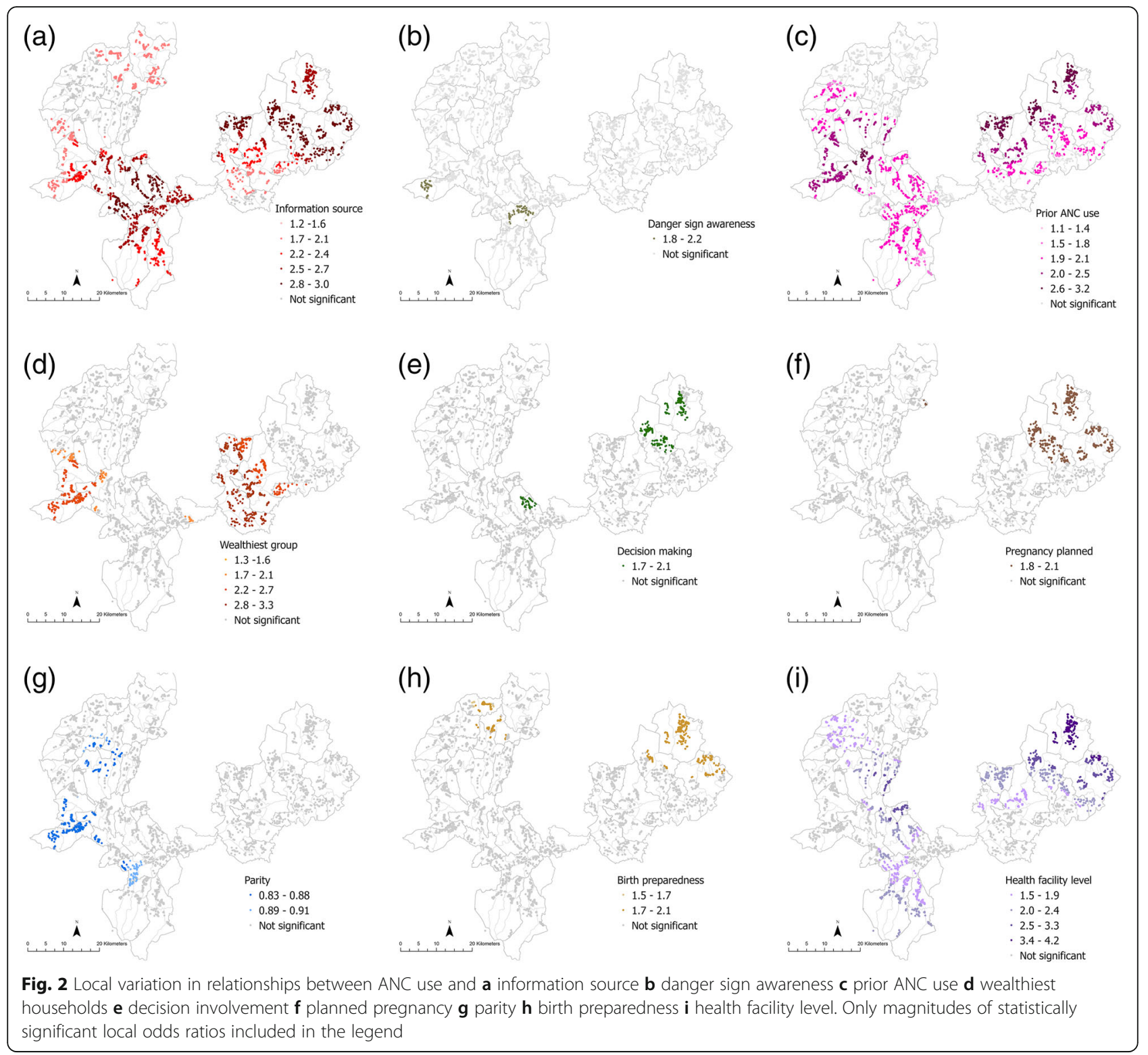

Non-stationarity in service use associations may also partially explain conflicting findings from different studies about what seems to be driving maternal health service use. Women's involvement in decisions about service use, for instance, has been described to be particularly important in patriarchal or hierarchical contexts where women are not primary decision makers [50-53]. However, while some studies find women's decisionmaking involvement to be significantly associated with service use [54-56], others have not [40, 57]. These studies originate from different districts and kebeles across Ethiopia and the results may partially be a consequence of this contextual diversity. In our study, we found involvement in health-related decision making to be a central factor affecting ANC use in very few kebeles. While these results do not downgrade the importance of women making their own decisions, they do raise the possibility that other factors with statistically significant local estimates may be more influential in some of these areas.

\section{Limitations}

Characteristics of husbands, such as their education levels, were not included in the models due to concerns about selection bias and missing data. These factors may represent important explanatory variables missing from our model which could 


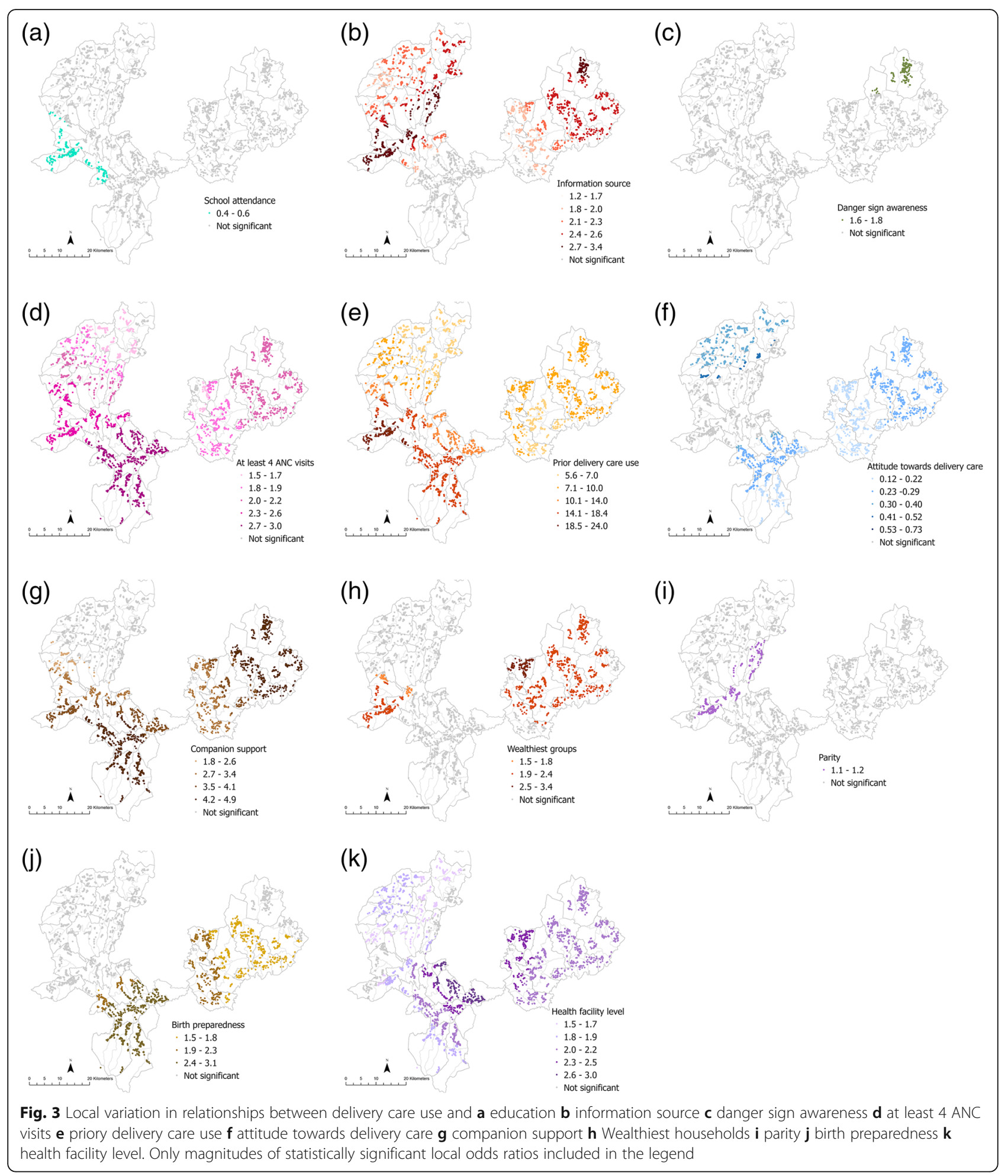

contribute to model misspecification and increase the likelihood of detecting spatial variation where none actually exists [27]. However, interpersonal and household variables such as decision making, social support and household wealth, were included which likely capture some of the important dimensions of husband influence. There is also an under-representation of health system factors (such as quality of care) and geographic factors (such as terrain) considered in our models. This reflects one of the limitations of GWR models where 


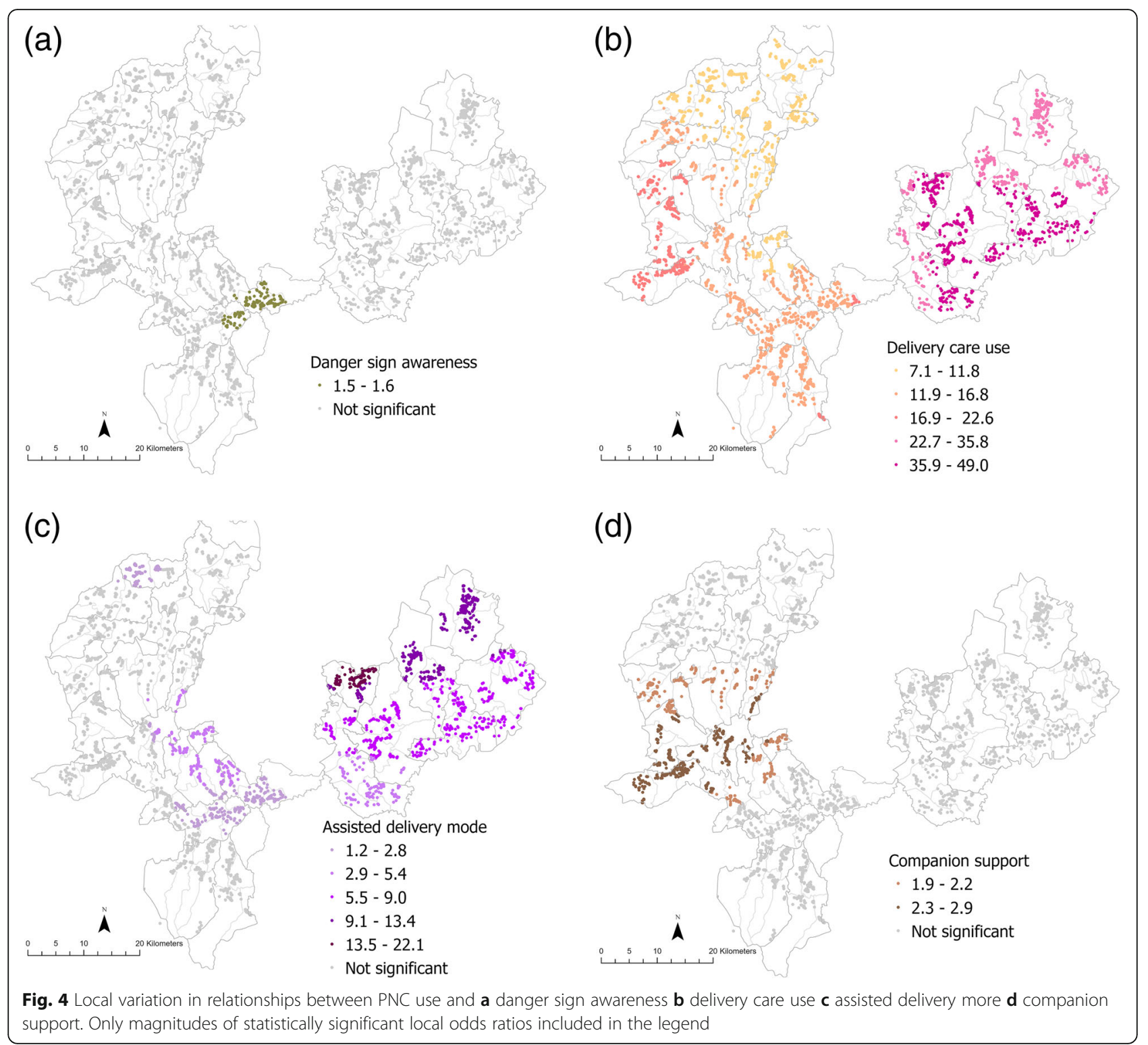

variables that do not have sufficient variability or that are common across large subsets of the data cannot be accommodated in the models.

A second limitation was related to the scale at which relationships between various explanatory factors and service outcomes were considered. Standard GWR models employ the use of a single bandwidth that is averaged across all independent variables in the model. This assumes that the relationships between each independent variable and the outcome operate at the same spatial scale [58]. Multiscale GWRs, which allow bandwidths to vary between explanatory variables, are currently not available for binary outcomes. However, bandwidth intervals can indicate the potential average spatial scales at which processes may be operating [59]. This may partially explain the spatial autocorrelation structure detected in the GWR residuals.

\section{Conclusions}

The presence of significant spatial variation in the relationships between service use and corresponding individual, interpersonal/household and health system factors highlights the importance of using analytic methods suited to capturing this variation adequately. GWR models facilitate the detection and exploration of this variability thus contributing to a more nuanced understanding of context-specific effects. The use of multiscale GWR models, that support the examination of relationship differences at several spatial scales, could further enhance this understanding. Consideration of local variability in the relative importance of factors influencing service use is critical for the design of equityoriented, responsive health systems and contextappropriate policy implementation. 


\section{Abbreviations}

AICc: Corrected Akaike Information Criterion; ANC: Antenatal care; Cl: Confidence interval; GWR: Geographically weighted regression; HEW: Health extension worker; MWH: Maternity waiting home; PHCU: Primary health care unit; PNC: Postnatal care; VDP: Variance decomposition proportion; VIF: Variance inflation factor

\section{Supplementary Information}

The online version contains supplementary material available at https://doi. org/10.1186/s12913-021-06379-3.

Additional file 1. Conceptual Model.

Additional file 2. Table of definitions of explanatory variables.

\section{Acknowledgements}

We are grateful to the communities who have been generous with their time and thoughts and without whom this trial would not be possible. A special thanks to Professor Stewart Fotheringham for thoughtfully and quickly answering several questions related to analysis. We would also like to express gratitude to Dr. Benoit Talbot who helped to work on generating path distances for earlier spatial analyses planned but ultimately not used. The authors would like to acknowledge the trial investigators from University of Ottawa (Prof Ronald Labonte) and Jimma University (Lakew Abebe Gebretsadik, Prof Sudhakar Morankar, Dr. Muluemebet Abera and Kunuz Bedru Haji) as well as the broader research team (Getachew Kiros, Abebe Mamo, Shifera Asfaw, Yisalemush Asefa, Gemechu Abene, Erko Endale, Nicole Bergen \& Corinne Packer).

\section{Authors' contributions}

JK conceptualized and performed the analysis and wrote the first draft of the manuscript. MK and MT provided feedback on the overall analytic approach while ZL provide methodological guidance for GWR modelling. CT provided support with use of GWR4 and acted as a helpful sounding board for analytic ideas. GB provided input on policy relevance to guide analytic decisions. All authors (JK, MK, CT, MT, GB, ZL) interpreted the findings, contributed to the development of the manuscript and approved the final manuscript.

\section{Funding}

This work was carried out with grants \#108028-001 (Jimma University) and \#108028-002 (University of Ottawa) from the Innovating for Maternal and Child Health in Africa initiative (co-funded by Global Affairs Canada (GAC), the Canadian Institutes of Health Research (CIHR) and Canada's International Development Research Centre (IDRC)); it does not necessarily reflect the opinions of these organizations. The funding agency had no role in design, data collection or analysis.

\section{Availability of data and materials}

Data used for this analysis will be provided upon reasonable request to $\mathrm{Dr}$. Manisha Kulkarni (manisha.kulkarni@uottawa.ca).

\section{Declarations}

\section{Ethics approval and consent to participate}

Ethical approval was obtained from the University of Ottawa Health Sciences and Science Research Ethics Board (File No: H10-15-25B and the Jimma University College of Health Sciences Institutional Review Board (Ref No: RPGE/449/2016). Informed consent for data collection was obtained from eligible women willing to participate in interviews prior to each round of household surveys. All research methods were carried out in accordance with the Canadian Tri-Council Policies Ethical Conduct for Research Involving Humans.

\section{Consent for publication}

Not applicable

\section{Competing interests}

The authors declare that they have no competing interests.

\section{Author details}

${ }^{1}$ School of Epidemiology and Public Health, University of Ottawa, 600 Peter Morand Crescent, Ottawa, Ontario K1G 5Z3, Canada. ${ }^{2}$ Jimma Zone Health Office, Jimma town, Jimma Zone, Oromia Region, Ethiopia. ${ }^{3}$ Ottawa Hospital Research Institute, Ottawa, Canada. ${ }^{4}$ Department of Geography \& Geographic Information Science, University of Illinois, Urbana, USA.

\section{Received: 18 December 2020 Accepted: 12 April 2021}

Published online: 12 May 2021

\section{References}

1. The Partnership for Maternal Newborn and Child Health. Opportunities for Africa's Newborns. Practical data, policy and programmatic support for newborns in Africa. Geneva; 2006.

2. Wang W, Alva S, Wang S, Fort A. Levels and trends in the use of maternal health services in developing countries. Calverton; 2011.

3. World Health Organization. Maternal health. Global situation [Internet]. 2020 [cited 2020 Oct 22]. Available from: https://www.who.int/health-topics/ma ternal-health\#tab=tab_2

4. World Health Organization. Maternal and newborn coverage [Internet]. 2020. [cited 2020 Oct 22]. Available from: https://www.who.int/data/materna I-newborn-child-adolescent-ageing/maternal-and-newborn-data/maternal-a nd-newborn\%2D\%2D-coverage

5. Requejo JH, Victora CG, Barros AJD, Berman P, Bhutta Z, Boerma T, et al. Countdown to 2015: a decade of tracking progress for maternal, newborn, and child survival. Geneva; 2015

6. Central Statistical Authority. Ethiopia Demographic \& Health Survey (2000). Addis Ababa \& Calverton; 2001.

7. Ethiopian Public Health Institute. Mini Demographic \& Health Survey (2019). Addis Ababa and Rockville; 2019.

8. United Nations. SDG indicators. Global SDG Indicator Database [Internet]. 2020. [cited 2020 Oct 22]. Available from: https://unstats.un.org/sdgs/indica tors/database/

9. Okedo-Alex IN, Akamike IC, Ezeanosike OB, Uneke CJ. Determinants of antenatal care utilisation in sub-Saharan Africa: a systematic review. BMJ Open. 2019;9(10):e031890. https://doi.org/10.1136/bmjopen-2019-031890.

10. Guliani H, Sepehri A, Serieux J. Determinants of prenatal care use: evidence from 32 low-income countries across Asia, sub-Saharan Africa and Latin America. Health Policy Plan. 2014;29(5):589-602. https://doi.org/10.1093/hea $\mathrm{pol} / \mathrm{czt045.}$

11. Diamond-Smith N, Sudhinaraset M. Drivers of facility deliveries in Africa and Asia: regional analyses using the demographic and health surveys. Reprod Health. 2015;12(6).

12. Langlois ÉV, Miszkurka M, Victoria M, Ghaffar A, Ziegler D, Karp I. Inequities in postnatal care in low- and middle-income countries: a systematic review and meta-analysis. Bull World Health Organ. 2015;93(4):259-70. https://doi. org/10.2471/BLT.14.140996.

13. Benova L, Owolabi O, Radovich E, Wong KLM, Macleod D, Langlois EV, et al. Provision of postpartum care to women giving birth in health facilities in sub-Saharan Africa: a cross-sectional study using demographic and health survey data from 33 countries. PLoS Med. 2019;16(10):e1002943. https://doi. org/10.1371/journal.pmed.1002943.

14. Chaka EE, Abdurahman AA, Nedjat S, Majdzadeh R. Utilization and determinants of postnatal care services in Ethiopia : a systematic review and meta-analysis. Ethiop J Health Sci. 2019;29(1):935-44.

15. Fotheringham AS, Brunsdon C, Charlton M. Geographically weighted regression. Chichester: Wiley; 2002.

16. Gangodagamage C, Zhou X, Lin H. Spatial autocorrelation. In: Shekhar S, Xiong H, editors. GIS encyclopedia. 2nd ed. Geneva: Springer International; 2016. p. 32-7. https://doi.org/10.1007/978-3-319-23519-6_83-2.

17. Kurji J, Talbot B, Bulcha G, Bedru KH, Morankar S, Gebretsadik LA, et al. Uncovering spatial variation in maternal healthcare service use at subnational level in Jimma Zone, Ethiopia. BMC Health Serv Res. 2020;20:703.

18. Moyer CA, Mustafa A. Drivers and deterrents of facility delivery in subSaharan Africa: a systematic review. Reprod Health. 2013;10:40.

19. Hill Z, Amare Y, Scheelbeek P, Schellenberg J. 'People have started to deliver in the facility these days': a qualitative exploration of factors affecting facility delivery in Ethiopia. BMJ Open. 2019;9:e025516.

20. Food and Agriculture Organization of the United Nations. Country profile Ethiopia. Geneva; 2016. 
21. Federal Democratic Republic of Ethiopia Ministry of Health. Health Sector Development Programme IV (2010/11-2014/15). Addis Ababa; 2010.

22. Oromia Bureau of Finance and Economic Development. Gomma district report. Jimma; 2016.

23. Jimma Zone Health Office. Jimma zone annual health bulletin. Jimma; 2016

24. Kurji J, Kulkarni MA, Gebretsadik LA, Wordofa MA, Morankar S, Bedru KH, et al. Effectiveness of Upgraded Maternity Waiting Homes and Local Leader Training in Improving Institutional Births among Women in Jimma Zone, Ethiopia: study protocol for a cluster randomized controlled trial. Trials. 2019;20:671.

25. Amouzou A, Hazel E, Sanni Y. Discordance in postnatal care between mothers and newborns : measurement artifact or missed. J Glob Health. 2020;10(1).

26. Kurji J, Gebretsadik LA, Wordofa MA, Morankar S, Bedru KH, Bulcha G, et al. Effectiveness of upgraded maternity waiting homes and local leader training on improving institutional births : a cluster- randomized controlled trial in Jimma. BMC Public Health. 2020;20:1593.

27. Comber A, Brunsdon C, Charlton M, Dong G, Harris R, Lü Y, et al. The GWR route map: a guide to the informed application of geographically weighted regression. 2020.

28. Pfeiffer DU, Robinson T, Stevenson M, Stevens KB, Rogers DJ, Clements ACA. Spatial analysis in epidemiology. Oxford: Oxford University Press; 2008. https://doi.org/10.1093/acprof:oso/9780198509882.001.0001.

29. Tobler WR. A computer movie simulating urban growth in the Detroit Region. Econ Geogr. 1970;46(Supplement):234-40.

30. Oshan TM, Li Z, Kang W, Wolf LJ, Fotheringham SA. MGWR: a python implementation of multiscale geographically weighted regression for investigating process spatial heterogeneity and scale. Int J Geo-Inf. 2019;6:269.

31. Wheeler D, Tiefelsdorf M. Multicollinearity and correlation among local regression coefficients in geographically weighted regression. J Geogr Syst. 2005;7(2):161-87. https://doi.org/10.1007/s10109-005-0155-6.

32. Fotheringham AS, Oshan TM. Geographically weighted regression and multicollinearity:dispelling the myth. J Geogr Syst. 2016;18(4):303-29. https:// doi.org/10.1007/s10109-016-0239-5.

33. Kim JH. Multicollinearity and misleading statistical results. Korean Anesthesiol. 2019;72(6):558-69. https://doi.org/10.4097/kja.19087.

34. ESRI. How Geographically weighted regression works [Internet]. 2020. [cited 2020 Sep 16]. Available from: https://pro.arcgis.com/en/pro-app/tool-reference/ spatial-statistics/how-geographicallyweightedregression-works.htm

35. Wheeler DC. Diagnostic tools and a remedial method for collinearity in geographically weighted regression. Environ Plan Ann. 2007;39(10):2464-82. https://doi.org/10.1068/a38325.

36. Da Silva RA, Fotheringham SA. The multiple testing issue in geographically weighted regression. Geogr Anal. 2016;48(3):233-47. https://doi.org/10.1111/ gean.12084

37. Tewodros B, Gebremariam A, Dibaba Y. Factors affecting antenatal care utilization in Yem special woreda, southwestern Ethiopia. Ethiop J Health Sci. 2009;19(1):45-50

38. Tadele N, Lamaro T. Utilization of institutional delivery service and associated factors in Bench Maji zone, Southwest Ethiopia: community based, cross sectional study. BMC Health Serv Res. 2017;17:101.

39. Worku AG, Yalew AW, Afework MF. Factors affecting utilization of skilled maternal care in Northwest Ethiopia : a multilevel analysis. BMC Int Health Hum Rights. 2013;13(20).

40. Dutamo Z, Assefa N, Egata G. Maternal health care use among married women in Hossaina, Ethiopia. BMC Health Serv Res. 2015;15:365.

41. Mekonnen ZA, Lerebo WT, Gebrehiwot TG, Abadura SA. Multilevel analysis of individual and community level factors associated with institutional delivery in Ethiopia. BMC Res Notes. 2015;8:376.

42. Mehari AM. Levels and determinants of use of institutional delivery care services among women of childbearing age in Ethiopia: analysis of EDHS 2000 and 2005 data. Calverton: DHS Working Papers; 2013.

43. Yebyo HG, Gebreselassie MA, Kahsay AB. Individual and community-level predictors of home delivery in Ethiopia: a multilevel mixed-effects analysis of the 2011 Ethiopia National Demographic and Health Survey. DHS Working Papers No. 104. 2014.

44. Mezmur M, Navaneetham K, Letamo G, Bariagaber H. Individual, household and contextual factors associated with skilled delivery care in Ethiopia: evidence from Ethiopian demographic and health surveys. PLoS One. 2017;12(9).
45. Arba MA, Darebo TD, Koyira MM. Institutional delivery service utilization among women from rural districts of Wolaita and Dawro Zones, Southern Ethiopia ; a community based cross-sectional study. PLoS One. 2016;11(3): e0151082. https://doi.org/10.1371/journal.pone.0151082.

46. Tunstall HVZ, Shaw M, Dorling D. Places and health. J Epidemiol Community Health. 2004;58(1):6-10. https://doi.org/10.1136/jech.58.1.6.

47. Mirzoev T, Kane S. What is health systems responsiveness? Review of existing knowledge and proposed conceptual framework. BMJ Glob Health. 2017;2:e000486.

48. Seeleman C, Essink-Bot M-L, Stronks K, Ingleby D. How should health service organizations respond to diversity? A content analysis of six approaches. BMC Health Serv Res. 2015;15:510.

49. Browne AJ, Varcoe CM, Wong ST, Smye VL, Lavoie J, Littlejohn D, et al. Closing the health equity gap: evidence-based strategies for primary health care organizations. Int J Equity Health. 2012;11:59.

50. Gabrysch S, Campbell OMR. Still too far to walk: literature review of the determinants of delivery service use. BMC Pregnancy Childbirth. 2009;9:34.

51. Kea AZ, Tulloch O, Datiko DG, Theobald S, Kok MC. Exploring barriers to the use of formal maternal health services and priority areas for action in Sidama zone, southern Ethiopia. BMC Pregnancy Childbirth. 2018;18:96.

52. King R, Jackson R, Dietsch E, Hailemariam A. Barriers and facilitators to accessing skilled birth attendants in Afar region, Ethiopia. Midwifery. 2015; 31(5):540-6. https://doi.org/10.1016/j.midw.2015.02.004

53. Finlayson K, Downe S. Why do women not use antenatal services in lowand middle-income countries? A meta-synthesis of qualitative studies. PLoS Med. 2013;10(1):e1001373. https://doi.org/10.1371/journal.pmed.1001373.

54. Fikre AA, Demissie M. Prevalence of institutional delivery and associated factors in Dodota Woreda (district), Oromia regional state, Ethiopia. Reprod Health. 2012;9:33.

55. Hailu D, Berhe H. Determinants of institutional childbirth service utilisation among women of childbearing age in urban and rural areas of Tsegedie district, Ethiopia. Midwifery. 2014;30(11):1109-17. https://doi.org/10.1016/j. midw.2014.03.009

56. Dida N, Birhanu Z, Gerbaba M, Tilahun D, Morankar S. Modeling the probability of giving birth at health institutions among pregnant women attending antenatal care in west Shewa zone, Oromia, Ethiopia: a cross sectional study. Afr Health Sci. 2014;14(2):288-98. https://doi.org/10.4314/a hs.v14i2.3.

57. Tiruneh FN, Chuang K, Chuang Y. Women's autonomy and maternal healthcare service utilization in Ethiopia. BMC Health Serv Res. 2017;17:718.

58. Fotheringham AS, Yang W, Kang W. Multiscale geographically weighted regression (MGWR). Ann Am Assoc Geogr. 2017;107(6):1247-65. https://doi. org/10.1080/24694452.2017.1352480.

59. Li Z, Fotheringham AS, Oshan TM, Wolf LJ. Measuring bandwidth uncertainty in multiscale geographically weighted regression using Akaike weights. Ann Am Assoc Geogr. 2020;110(5):1500-20. https://doi.org/10.1 080/24694452.2019.1704680

\section{Publisher's Note}

Springer Nature remains neutral with regard to jurisdictional claims in published maps and institutional affiliations.

Ready to submit your research? Choose BMC and benefit from:

- fast, convenient online submission

- thorough peer review by experienced researchers in your field

- rapid publication on acceptance

- support for research data, including large and complex data types

- gold Open Access which fosters wider collaboration and increased citations

- maximum visibility for your research: over $100 \mathrm{M}$ website views per year

At BMC, research is always in progress.

Learn more biomedcentral.com/submissions 